\title{
Geographical inequality in cataract surgery among Iranians between 2006 and 2011
}

Cyrus Alinia, ${ }^{1}$ Seyed-Farzad Mohammadi, ${ }^{2}$ Mahmoud Jabbarvand ${ }^{2}$ and Hasan Hashemi ${ }^{3}$

${ }^{1}$ Department of Public Health, School of Public Health, Urmia University of Medical Sciences, Urmia, Islamic Republic of Iran. ${ }^{2}$ Translational Ophthalmology Research Center, Farabi Eye Hospital, Tehran University of Medical Sciences, Tehran, Islamic Republic of Iran (Correspondence to: Seyed-Farzad Mohammadi: sfmohammadi@tums.ac.ir). ${ }^{3}$ Noor Ophthalmology Research Center, Tehran, Islamic Republic of Iran.

\begin{abstract}
Background: Cataract surgery is a highly cost-effective intervention for sight restoration but inequalities exist in its use which health care systems should aim to reduce.

Aims: This study aimed to measure the level of inequality in cataract surgery use and the changes in inequality between 2006 and 2011 in the Islamic Republic of Iran.

Methods: A number of metrics, including ranges and indexes based on Lorenz curves (Gini, concentration and dissimilarity indexes), were used to measure the inequality in cataract surgery use among Iranians in 2006 and 2011. Cataract surgical numbers and socioeconomic data were obtained from a province-based survey and the national census database.

Results: Significant inter-provincial and inter-regional differences were found in cataract surgical proportions. South Khorasan province had the lowest cataract surgical rate in 2006 and 2011, while Tehran province had the highest rate in both years. Inequality in the distribution of cataract surgery services decreased between 2006 and 2011: the Gini, concentration and dissimilarity indexes decreased by $0.028,0.03$ and 0.037 , respectively. However, cataract surgery delivery remained in favour of the better-off provinces.
\end{abstract}

Conclusions: To reduce this inequality, policy-makers should improve financial and physical access to cataract surgery, especially in the relatively deprived provinces, and tackle physician-induced demand.

Keywords: Cataract surgery, inequality, Gini index, socioeconomic factors, Iran.

Received: 05/04/16; accepted: 16/07/17

Citation: Alinia C; Mohammadi S-F; Jabbarvand M; Hashemi H. Geographical inequality in cataract surgery among Iranians between 2006 and 2011. East Mediterr Health J. 2018;24(7):664-671. https://doi.org/10.26719/2018.24.7.664

Copyright ( C World Health Organization (WHO) 2018. Some rights reserved. This work is available under the CC BY-NC-SA 3.0 IGO license (https:// creativecommons.org/licenses/by-nc-sa/3.o/igo).

\section{Introduction}

Cataract is the second leading cause of visual impairment after uncorrected refractive errors, and is responsible for $33 \%$ of visual impairment and half of the cases of blindness worldwide $(1,2)$. The epidemiological burden of cataract has increased by $12 \%$ in the past two decades (3). Patients with cataract lose about $40 \%$ of their total healthrelated quality of life that can be recovered by cataract surgery (4), which is a highly cost-effective intervention with excellent prognosis for sight restoration (5). VISION 2020: the Right to Sight is an international drive to increase cataract surgical services in order to reduce the cataract "backlog" of people needing cataract surgery (6).

One of the landmark indicators in the assessment of eye care programmes, particularly in developing countries, is the cataract surgical rate, which is the number of cataract surgeries performed per million population per year. Cataract surgery utilization varies between populations of different socioeconomic status, and is generally lower among the poor, which is attributed to unequal availability and affordability of cataract surgery. This study aimed to investigate the avoidable total inequality and income-related inequality in the use of cataract surgery and the change in inequality between 2006 and 2011 in the Islamic Republic of Iran. We used a comprehensive spectrum of metrics, such as ranges and Lorenz curves based on subnational data. To our knowledge, this has not been done before in the field of ophthalmology.

The Lorenz curve is a tool for describing resource distribution. It indicates which proportion of the total cataract surgical number is in the hands of a given percentage of the population by relating the cumulative proportion of cataract surgical number to the cumulative proportion of various income groups (7). The curve was originally used to represent the size distribution of income and wealth (8) but in recent years it has been used to monitor policies for allocation of health care resources (9-11).

\section{Methods}

\section{Data sources}

The cataract surgical numbers for 2006 and 2011 were obtained from a province-based cross-sectional survey in the Islamic Republic of Iran. The sampling and data collection method are reported elsewhere (12). The Statistics Centre of Iran provided the national 2006 and 2011 census data for other required information such as population socioeconomic data, in particular the gross annual household per capita income and household 
dimensions. We prepared a data profile containing the subnational (province and region) cataract surgical numbers and their related population factors to measure the inequality in the cataract surgical rate.

\section{Data analysis}

To describe the national distribution of the population adjusted for cataract surgical number, we applied range indicators such as absolute range, range ratio, coefficient of variation and the Mcloone index to determine the income-related unequal distribution of cataract surgery use among Iranians. For the time-trend, we used the Gini concentration and dissimilarity indicators.

\section{Range indicators}

Range is simply the difference between the highest and lowest adjusted cataract surgical number. Range ratio is calculated by dividing the adjusted cataract surgical number at the 95th centile by the value at the 5 th centile. Range is skewed by outliers, while this issue is solved with the range ratio (13).

The Mcloone index, which takes a much larger proportion of the data into account than the range ratio index, is the sum of all adjusted cataract surgical numbers at or below the median divided by the median multiplied by the number of observations at or below the median. Values range between zero and one (14). The coefficient of variation (15) considers the dispersion of all data points around the mean (14).

\section{Indicators based on Lorenz curves}

The Gini coefficient is equal to 1 minus twice the area under the Lorenz curve, and the output ranges between zero (no inequality) and 1 (maximum inequality).

The concentration index quantifies the degree of socioeconomic-related inequality in a health variable (16). The concentration curve is the cumulative proportion of the cataract surgical number shown against the cumulative population proportion when the population is arranged in order of adjusted income by household dimension (socioeconomic variable) (17). The concentration index ranges between -1 and +1 ; it is negative when the curve lies above the line of equality (disproportionate concentration among the poor), positive when it lies below the line of equality, and zero when there is no socioeconomic-related inequality (9). For a favourable variable such as cataract surgical number, a positive concentration index value means the cataract surgical number is higher among the rich (18).

The index of dissimilarity allows us to observe intra-population variations and analyses how much of a change is needed to achieve perfect equality (19). The lower the value of the index of dissimilarity the less the inequality (20).

\section{Methodological adjustments to the model}

The Islamic Republic of Iran has 31 provinces; these boundaries are not a barrier to receiving health care because everyone can obtain services in any province. Thus, we measured inequality indicators by province and region. To minimize information bias with regionbased indices, the following were taken into account for grouping: the neighbouring provinces, having physical access (ophthalmologist per capita and geographical distance between patient and provider), existence of an ophthalmology residency training centre, existence of ophthalmology centres and a referral system, and the results of an interview with university authorities to determine where cataract patients were referred. Based on these factors, Iranian provinces were grouped into 9 regions (Table 1 ).

Data on cataract surgical number for 3 provinces (Ilam, Kohgiluyeh \& Boyer-Ahmad and Zanjan) were not available and they were excluded from the analysis. Kerman was divided in regions 2 and 5 with a coefficient of 0.5 because of its large area and being next to the two

\begin{tabular}{|c|c|c|c|}
\hline \multirow{2}{*}{$\begin{array}{l}\text { Region } \\
\text { No. }\end{array}$} & \multirow[t]{2}{*}{ Province } & \multicolumn{2}{|c|}{ Population } \\
\hline & & 2006 & 2011 \\
\hline 1 & North Khorasan, South Khorasan, Razavi Khorasan & 7423660 & 7524663 \\
\hline 2 & Sistan \& Baluchestan, Hormozgan, Kerman ${ }^{a}$ & 5487572 & 5582004 \\
\hline 3 & $\begin{array}{l}\text { Tehran, Golestan, Mazandaran, Gilan, Markazi, Qom, } \\
\text { Qazvin, Semnan }\end{array}$ & 25943822 & 26326152 \\
\hline 4 & $\begin{array}{l}\text { Esfahan, Kohgiluyeh \& Boyer Ahmad, Chaharmahal \& } \\
\text { Bakhtiari }\end{array}$ & 5700029 & 5774575 \\
\hline 5 & Yazd, Kerman ${ }^{a}$ & 2495990 & 2543922 \\
\hline 6 & Fars, Bushehr & 5543701 & 5629607 \\
\hline 7 & Khuzestan, Ilam, Lorestan & 6225223 & 6285963 \\
\hline 8 & Kurdistan, Kermanshah, Hamedan & 5161561 & 5197140 \\
\hline 9 & West Azerbaijan, East Azerbaijan, Zanjan, Ardabil & 6995853 & 7053684 \\
\hline
\end{tabular}

${ }^{a}$ Because of its large area, Kerman province is divided into 2 parts; the northern part is included in region 2 and its southern part is included in region 5 
Table 2 Range indicators of inequality in cataract surgery utilization in the Islamic Republic of Iran, 2006 and 2011

\begin{tabular}{lcccc} 
Year & Absolute range & Range ratio & Coefficient of variation & Mcloone index \\
\hline Provincial inequality & & & & 0.450 \\
2006 & 139122 & 54.48 & 1.85 & 0.518 \\
2011 & 151383 & 75.22 & 1.61 & 0.621 \\
Regional inequality & & & 1.26 & 0.735 \\
\hline 2006 & 179911 & 24.94 & 1.07 & \\
2011 & 198212 & 9.600 & & \\
\hline
\end{tabular}

referral centres of Sistan \& Baluchistan in the south and Yazd in the north. All data were analysed with Microsoft Excel and the distribution plotted with geographic information system (GIS) software.

\section{Ethical considerations}

The protocol for this survey was approved by the Tehran University of Medical Sciences, and ethics approval was granted by the Human Research Ethics Committee at the university. The tenets of the Declaration of Helsinki were followed throughout.

\section{Results}

Overall, we found significant differences in the cataract surgical rates between the provinces and regions. In 2006 and 2011, South Khorasan had the lowest cataract surgical rate while Tehran had the highest. The province-based absolute range over the studied time period increased by 12261 surgeries. In addition, the province range ratio of cataract surgical number showed a 1.38 times increase while the region-based ratio had a 2.6 times decline. Other range indicators confirm the decreasing trend of both provincial and regional inequality in cataract surgery utilization, although related inequality values are still high. The coefficient of variation index decreased by 0.24 and 0.19 in province and region-based analyses respectively, indicating decreased service utilization within the population. As shown in Figure 1, concentration of cataract surgical rate was mainly in the western half of the country and there was little change in its distribution from 2006 to 2011.

If we accept the median value of national cataract surgical rate as a reasonable benchmark, the Mcloone index shows that a larger proportion of provinces are reaching this median over time, so that the higher Mcloone index in both provincial and regional divisions over the two time periods supports increased equality in access to cataract surgery services. However, there are still large gaps, especially between provinces (Table 2). The Gini coefficient decreased by $13.8 \%$ in 5 years, similarly the concentration index and dissimilarity index decreased by $15.0 \%$ and $16 \%$ over this time period respectively (Table 3 ).

High-income provinces have the largest proportion of the Iranian population and use cataract surgery services the most, while provinces with a predominantly middle- income population have the lowest population proportion and cataract surgery use; rates are disproportionate in both groups (Table 3). Stratifying the provinces by household per capita income into five income quintiles showed that the Gini index was highest in the middle per capita income category (highest inequality) and lowest in the fourth quintile in both years, and there was a decreasing trend in all quintiles and hence in the total. Nevertheless, substantial cross-province differences were observed in the level of equality in the cataract surgical rate.

The regional-based Gini index decreased by $66.4 \%$ and the concentration index declined by $29.6 \%$. The $29.8 \%$ decrease in the dissimilarity index indicates that the decrease in inequality has reduced the need for relocation of resources for cataract surgery services from more affluent provinces to relatively deprived provinces by $29.8 \%$ (Table 4).

\section{Discussion}

\section{Key findings}

Our findings show substantial avoidable income-related inequality in cataract surgery delivery between provinces, although we identified a trend towards some decreased inequality in the distribution of cataract surgery services from 2006 to 2011. Region-based inequality analysis showed the same trend but considerably lower inequality for both years and all measures. The inequality in cataract surgery delivery in favour of the better-off means that there is an unequal distribution of cataract surgery providers across the country which favours the higher income provinces. The three main reasons for this are: existing differences in socioeconomic and health status, the health care referral system, and financial incentives for providers.

\section{Socioeconomic and health status}

The more developed the province, the higher the purchasing power and education level of the population, and thus the better the financial and informational access to health care services it has, such as cataract surgery, and the higher the utilization rates (21). Given that life expectancy in the more prosperous provinces is higher than the poorer provinces and cataract is an age-related disease, a higher incidence of cataract disorders is expected in the 


\begin{tabular}{|c|c|c|c|c|c|c|c|c|c|}
\hline $\begin{array}{l}\text { Income } \\
\text { group }\end{array}$ & Year & $\begin{array}{l}\text { No. of } \\
\text { CS }\end{array}$ & $\begin{array}{l}\text { Rel. \% } \\
\text { CS }\end{array}$ & $\begin{array}{l}\text { Cumul. \% } \\
\text { CS }\end{array}$ & $\begin{array}{l}\text { Rel. \% } \\
\text { Pop. }\end{array}$ & $\begin{array}{l}\text { Cumul. \% } \\
\text { Pop. }\end{array}$ & $\begin{array}{l}\text { Gini } \\
\text { index }\end{array}$ & $\begin{array}{l}\text { Concentration } \\
\text { index }\end{array}$ & $\begin{array}{l}\text { Dissimilarity } \\
\text { index }\end{array}$ \\
\hline \multirow[b]{2}{*}{ Poorest } & 2006 & 36276 & 9.3 & 9.3 & 13.3 & 13.3 & 0.143 & 0.026 & 0.246 \\
\hline & 2011 & 50849 & 10.1 & 10.1 & 13.2 & 13.2 & 0.024 & -0.14 & 0.188 \\
\hline \multirow{2}{*}{ 2nd } & 2006 & 45731 & 11.7 & 21 & 16.8 & 30.1 & 0.086 & 0.025 & 0.087 \\
\hline & 2011 & 58564 & 11.7 & 21.8 & 16.8 & 30.0 & 0.02 & 0 & 0.099 \\
\hline \multirow[b]{2}{*}{ 3rd } & 2006 & 23907 & 6.1 & 27.1 & 11.5 & 41.6 & 0.21 & -0.137 & 0.274 \\
\hline & 2011 & 35627 & 7.1 & 28.9 & 11.5 & 41.5 & 0.164 & 0.051 & 0.273 \\
\hline \multirow[b]{2}{*}{ 4th } & 2006 & 66044 & 16.9 & 44 & 17.9 & 59.5 & 0.024 & -0.045 & 0.146 \\
\hline & 2011 & 71828 & 14.3 & 43.2 & 17.9 & 59.4 & 0.012 & -0.078 & 0.186 \\
\hline \multirow{2}{*}{ Richest } & 2006 & 218911 & 56.0 & 100 & 40.5 & 100 & 0.14 & 0.148 & 0.169 \\
\hline & 2011 & 285627 & 56.8 & 100 & 40.6 & 100 & 0.054 & 0.041 & 0.068 \\
\hline \multirow{2}{*}{$\begin{array}{l}\text { Total/ } \\
\text { average }\end{array}$} & 2006 & 13934 & 100 & - & 100 & - & 0.203 & 0.2 & 0.232 \\
\hline & 2011 & 502495 & 100 & - & 100 & - & 0.175 & 0.17 & 0.195 \\
\hline
\end{tabular}

\begin{tabular}{llllll}
\hline Table 4 Regional inequality in cataract surgery utilization in the Islamic Republic of Iran in $\mathbf{2 0 0 6}$ and 2011 & Dissimilarity index \\
\hline Year & $\begin{array}{l}\text { No. of cataract } \\
\text { surgeries }\end{array}$ & Population size & Gini index & $\begin{array}{l}\text { Concentration } \\
\text { index }\end{array}$ & . \\
\hline $\mathbf{2 0 0 6}$ & 390869 & 70977413 & 0.113 & 0.054 & 0.168 \\
$\mathbf{2 0 1 1}$ & 502495 & 71917710 & 0.038 & 0.038 & 0.118 \\
\hline
\end{tabular}

prosperous provinces and so its higher cataract surgical rate is not attributed to inequality.

These results should be interpreted with caution because it seems likely that this relationship results from an ecological fallacy. All we know is that there is a positive and significant relationship between higher income provinces and rate of cataract surgery. But, this does not necessarily mean a positive causal relationship between income level and the number of cataract surgeries. Since the individual-level data are not available, we cannot evaluate the ecological fallacy related to the findings.

During the 2 time periods of the study, inter-provincial socioeconomic inequalities in cataract surgery utilization fell from 0.2 to 0.17 . This confirms the existence of avoidable inequalities favouring the rich. Changes in income-related inequalities were not the same across all five income quintiles; resource allocation, whether intentional or unintentional, has changed the winners and losers over time. In 2006, concentration indexes were negative for the 3rd and 4th income quintiles, meaning a pro-poor inequality in cataract surgery use. In 2011, the concentration index for the first (poorest) quintile became negative and the fourth remained negative, while the concentration index in the middle-class provinces (3rd quintile) shifted from below the equality line to above, therefore suggesting the richest utilized cataract surgery more than the poorest. In income categories with a positive concentration index, in order to remove income-related inequality, cataract surgery services need to be transferred from higher to lower income provinces, which would lead to a bivariate concentration index close to zero. The dissimilarity index, on the one hand confirms the Gini coefficient index and concentration index results, and on the other hand indicates that in order to disperse cataract surgery services evenly or equally across the country, $75.1 \%$ of these deliveries should have moved from high-income provinces to low-income ones in 2011. This need for resource reallocation was lower $(64.8 \%)$ in 2006 . Given the different inequality figures in the income quintiles, the need for a shift in resources to achieve equality in cataract surgery utilization varies between them as well. This need was highest for the middle-income group in 2006 and 2011, and lowest for the second income quintile in $2006(8.7 \%)$ and richest provinces in 2011 (6.8\%). 
Figure 1 Distribution of population-adjusted cataract surgery in 2006 and 2011 in the Islamic Republic of Iran (CSR = cataract surgical rate)

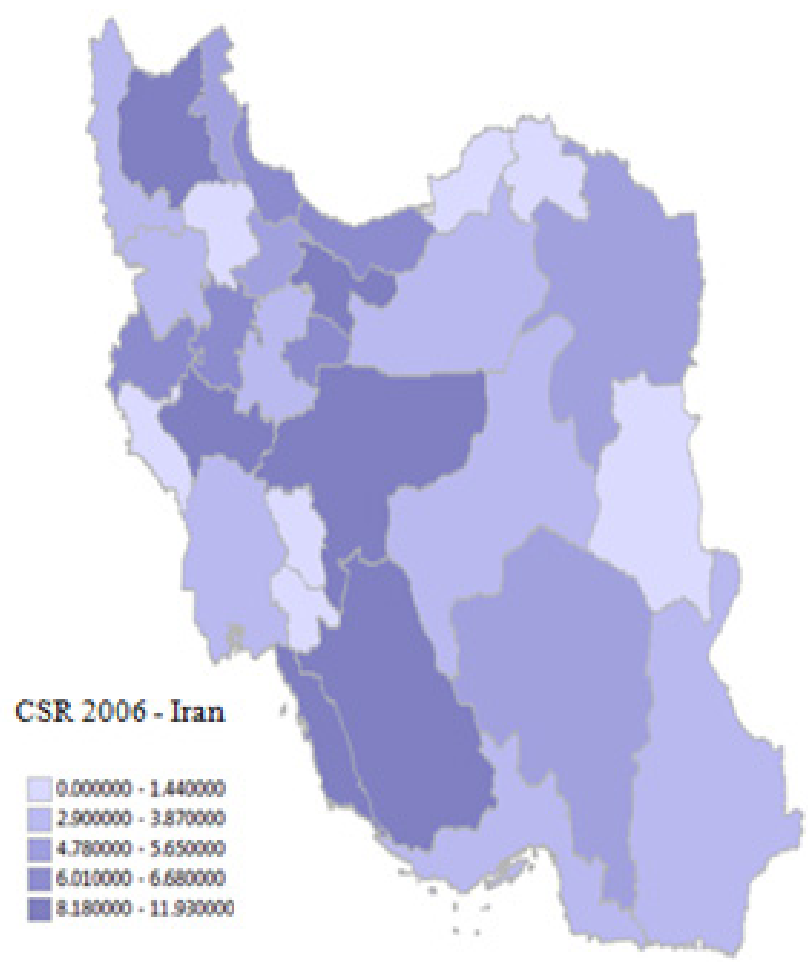

\section{Iranian health care referral system}

Specialty and subspecialty care are in the second and third levels of the health care referral system in the Islamic Republic of Iran. Cataract surgery is often done by general ophthalmologists who work within the second level in all provinces. Complicated cases are referred to anterior segment ophthalmologists in the third level in the few subspecialty ophthalmology centres and hospitals and these are concentrated in the more developed provinces. This referral system has two macro effects on inequality in the cataract surgical rate. By establishing modern ophthalmic care centres in more developed provinces, particularly in the capital, Tehran, physical access, as measured by ophthalmologist per capita and geographical distance between patient and provider, has been increasing for adjacent cities and provinces and decreasing for remoter regions. The concentration of resources, including ophthalmic specialists and technologies, increases cataract surgery supply in high-income provinces; at the same time it attracts more ophthalmologists to those areas. Overall, this results in inequality in cataract surgery utilization which favours the richest.

\section{Provider incentives}

According to the microeconomic profit-maximization theory, all firms or providers, such as ophthalmologists, behave in a manner that returns the greatest profit by determining the price and number of cataract surgery. The opportunity to work in the private sector, where fees are higher, attracts ophthalmologists to more developed

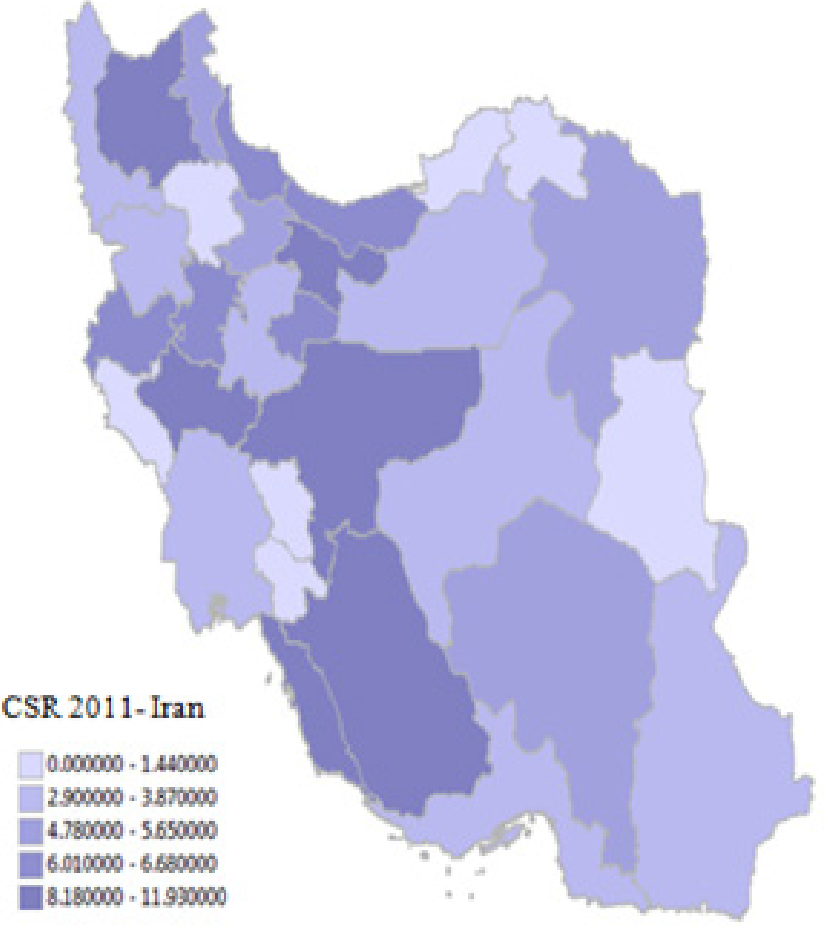

provinces. Another notable incentive-related issue with cataract surgery is the ophthalmologist-induced demand that may be higher in high-supply areas such as more developed provinces. Performing early cataract surgery to maximize surgeon profit regardless of patient need can artificially increase utilization inequality (22).

\section{Policy implications and the future}

Some of the reasons mentioned earlier for the inequality in cataract surgery utilization, including differences in the socioeconomic and health status of patients, a weak referral system, and physician-induced demand, are not justifiable and must be resolved. Other reasons, such as differences in cataract surgery need, are understandable but should be considered in order to achieve equity in cataract surgery utilization. To eliminate inequality between provinces, all factors related to access (physical, financial and informational) and supplier-induced demand should be removed and the distribution of ophthalmologists adjusted. As a way to decrease access inequality, the Ministry of Health and Medical Education policy requires that newly graduated ophthalmologists are assigned to facilities across the country as part of their mandatory service on graduation. However, our results indicate that this scheme has had very little success. We recommend the following policies in order to eliminate the inequality in access to cataract surgery services.

1. Resource redistribution: Avoidable cataract surgery inequality can be decreased significantly by redistributing and improving the infrastructure through provision of necessary resources - budgetary 
resources, trained and skilled human resources, and technology resources - in favour of the poorer provinces. However, decreased inequality does not necessarily imply service adequacy, but rather reduced differences in resource allocation between different groups.

2. Access improvement: Since utilization is a manifestation of factors related to access (financial, physical and informational), policy-makers should ensure that all these access factors are tackled using appropriate measures. Resource redistribution to bring providers closer to those with cataracts may solve the physical access problem, but does not guarantee cataract surgery utilization by patients who need it. Many cases of untreated cataract are due to financial barriers or even lack of sufficient information about the availability and effectiveness of cataract surgery. Therefore, insurance coverage for cataract surgery and increasing health literacy, particularly in deprived and remote areas, using social media should improve financial and informational access respectively (23).

A further study with more focus on evaluating physicianinduced cataract surgery and also the level of need for cataract surgery among different strata of the population is therefore recommended. A decomposition study can determine the contribution of each significant socioeconomic variable and help policy-makers control the determinants of inequality in cataract surgery utilization.

\section{Limitations}

Inequality measures greatly depend on the data types (individual or group levels), ranking types (based on, for example, income, wealth, expenditure, education), and the degree of freedom of the data. In our study, data selection was based on availability, possibility, and adequacy. In this regard, lack of data limited our ability to define socioeconomic determinants or differences within provinces or on an individual level. Another limitation was the lack of data on disposable household income so we had to use data on gross household income.

Funding: This study was partially supported by Hormoz Chams Research Chair in Public Health Ophthalmology, Allama Tabatabaei Award, National Elite Foundation (http://bmn.ir/).

Competing interests: None declared.

\section{Opération de la cataracte parmi les Iraniens en 2006 et 2011 : inégalités géographiques}

\section{Résumé}

Contexte : L'opération de la cataracte est une intervention de restauration de la vue ayant un très bon rapport coûtefficacité, mais des inégalités existent quant à la possibilité d'en bénéficier, et il est du ressort des systèmes de soins de santé de s'efforcer de les réduire.

Objectif : La présente étude avait pour objectif de mesurer le niveau d'inégalité en matière de recours à l'opération de la cataracte, ainsi que les changements en termes d'inégalités entre 2006 et 2011 en République islamique d'Iran.

Méthodes : Un certain nombre de mesures, dont des étendues et des indices reposant sur la courbe de Lorenz (coefficient de Gini, indices de concentration et de dissimilarité) ont été utilisés afin de mesurer les inégalités en matière d'opération de la cataracte parmi les Iraniens en 2006 et en 2011. Le nombre d'opérations de la cataracte et des données socioéconomiques ont été obtenus au moyen d'une étude réalisée dans les provinces et à partir de la base de données de recensement national.

Résultats: Des différences interprovinciales et interrégionales ont été trouvées concernant le taux de recours à la chirurgie de la cataracte. Le Khorasan méridional affichait le taux d'opération de la cataracte le plus bas en 2006 et 2011, tandis que la province de Téhéran avait le taux le plus élevé pour les deux années. Les inégalités en matière de distribution des services d'opération de la cataracte ont diminué entre 2006 et 2011, le coefficient de Gini et les indices de concentration et de dissimilarité ayant respectivement baissé de 0,028,0,03 et 0,037. Néanmoins, l'opération de la cataracte reste davantage pratiquée dans les provinces plus riches.

Conclusion: Afin de réduire ces inégalités, les responsables politiques devraient améliorer l'accès à l'opération de la cataracte, tant au niveau financier qu'en termes de disponibilité d'infrastructures pratiquant ce type d'opération, notamment dans les provinces relativement pauvres. Pour ce faire, il convient également de s'attaquer au problème de la demande induite par les médecins.

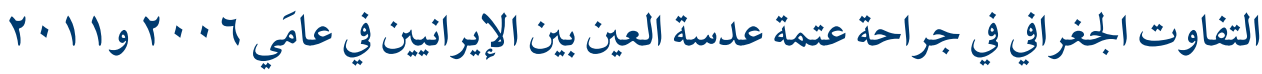

$$
\begin{aligned}
& \text { سيروس علي نيا، سيد فرزاد محمدي، محمود جباروند، حسن هاشمي } \\
& \text { الخالاصة } \\
& \text { الخلفية: إن جر احة عتمة عدسة العين تدخل فعال للغاية من حيث التكلفة لاستعادة البصر، ولكن هناك أوجه لعدم المساواة في الاستفادة من هذه }
\end{aligned}
$$




$$
\text { الجراحة، وينبغي لنظم الرعاية الصحية أن تهدف إلى الحددمن ذلك. }
$$

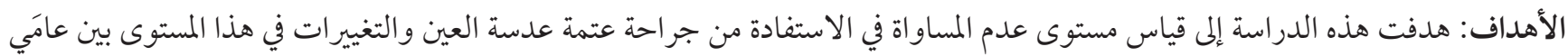

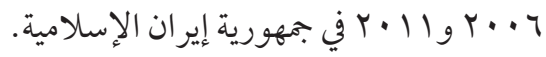

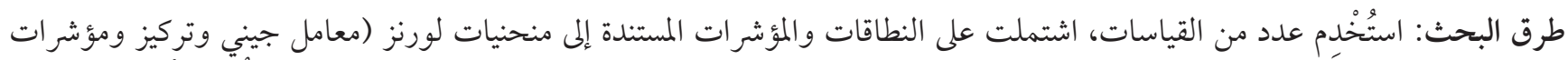

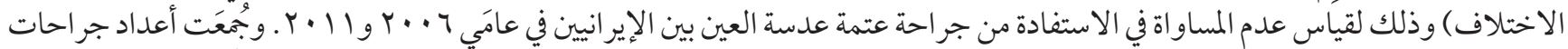

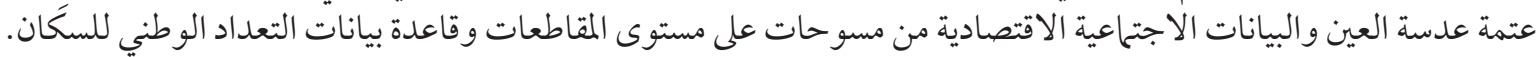

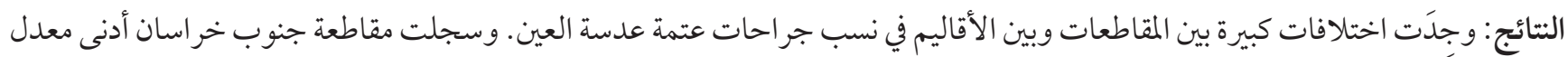

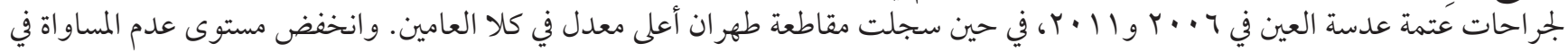

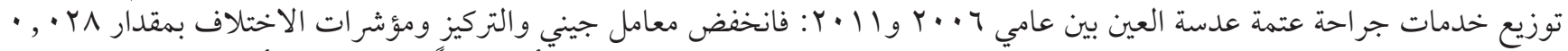

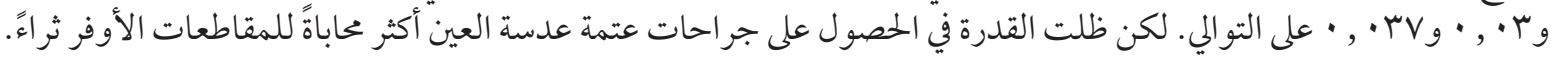

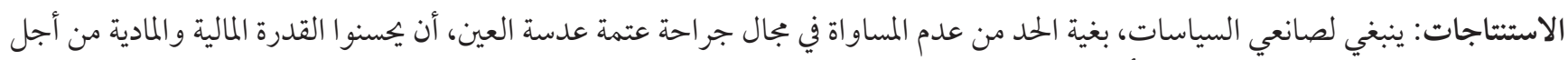

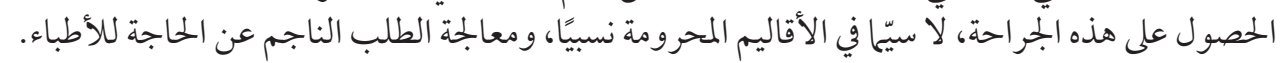

\section{References}

1. Pascolini D, Mariotti SP. Global estimates of visual impairment: 2010. Br J Ophthalmol. 2012 May 1;96(5):614-8. http://dx.doi. org/10.1136/bjophthalmol-2011-300539 PMID:22133988

2. Bourne RR, Stevens GA, White RA, Smith JL, Flaxman SR, Price H, et al. Causes of vision loss worldwide, 1990-2010: a systematic analysis. The Lancet Glob Health. 2013 Dec 1;1(6):e339-49. https://doi.org/10.1016/S2214-109X(13)70113-X PMID:25104599

3. Murray CJ, Vos T, Lozano R, Naghavi M, Flaxman AD, Michaud C, et al. Disability-adjusted life years (DALYs) for 291 diseases and injuries in 21 regions, 1990-2010: a systematic analysis for the Global Burden of Disease Study 2010. Lancet. 2012 Dec 15;380(9859):2197-223. https://doi.org/10.1016/So140-6736(12)61689-4 PMID:23245608

4. Yousefi M, Sheikhrobat YB, Najafi S, Ghaffari S, Ghaderi H, Memarzadeh SE, et al. Mapping catquest scores onto EQ-5D utility values in patients with cataract disease. Iran Red Crescent Med J. 2017;19(5):e21928. https://doi.org/10.5812/ircmj.21928.

5. Eye Care Comparative Effectiveness Research Team. Cost-utility analysis of cataract surgery in Japan: a probabilistic Markov modeling study. Jpn J Ophthalmol. 2013 Jul 1;57(4):391-401. https://doi.org/10.1007/s10384-013-0238-8 PMID:23588297

6. Pascolini D, Mariotti SP. Global estimates of visual impairment: 2010. Br J Ophthalmol. 2012 May;96(5):614-8. https://doi. org/10.1136/bjophthalmol-2011-300539 PMID:22133988.

7. Bellù LG, Liberati P. Charting income inequality: the Lorenz curve. Munich Personal RePEc Archive. 2005 (https://mpra.ub.unimuenchen.de/30063/1/MPRA_paper_30063.pdf, accessed 26 February 2018).

8. Kakwani NC. Applications of Lorenz curves in economic analysis. Econometrica. 1977;45(3):719-28.

9. O'Donnell OA, Wagstaff A. Analyzing health equity using household survey data: a guide to techniques and their implementation. Washington (DC): World Bank Publications; 2008.

10. Matsumoto M, Inoue K, Bowman R, Kajii E. Self-employment, specialty choice, and geographical distribution of physicians in Japan: A comparison with the United States. Health Policy. 2010 Aug;96(3):239-44. https://doi.org/10.1016/j.healthpol.2010.02.008 PMID:20223549

11. Munga MA, Maestad O. Measuring inequalities in the distribution of health workers: the case of Tanzania. Hum Resour Health. 200901 21;7(1):4. https://doi.org/10.1186/1478-4491-7-4 PMID:19159443

12. Hashemi H, Rezvan F, Khabazkhoob M, Gilasi H, Etemad K, Mahdavi A, et al. Trend in cataract surgical rate in Iran provinces. Iran J Public Health. 2014 Jul;43(7):961-7. PMID:25909063

13. Verstegen DA. Concepts and measures of fiscal inequality: A new approach and effects for five states. J Educ Finance. 1996;22(2):145-60.

14. Hale T. The theoretical basics of popular inequality measures; online computation of examples. Austin (TX): University of Texas Inequality Project, University of Texas at Austin; 2003.

15. Salkind N. Encyclopedia of research design. Thousand Oaks (CA): Sage; 2010

16. Kakwani N, Wagstaff A, Van Doorslaer E. Socioeconomic inequalities in health: measurement, computation, and statistical inference. J Econom. 1997;77(1):87-103. https://doi.org/10.1016/S0304-4076(96)01807-6

17. Podder N. On the relationship between the Gini coefficient and income elasticity. Sankhyā: India J Statistics. 1995;57(Series B, Pt. 3:428-32.

18. Jenkins S. Calculating income distribution indices from micro-data. Natl Tax J. 1988;41(1):139-42.

19. González Cancelas N, Palomino Monzón MC, Soler Flores FJ, Almazan Garate JL. Gini coefficient, dissimilarity index and Lorenz 
curve for the Spanish port system by type of goods. 1st International Virtual Scientific Conference, 10-14 June 2013 (http:// oa.upm.es/26179/1/INVE_MEM_2013_162918.pdf, accessed 25 February 2018).

20. Palmore E, Whittington FJ. Differential trends toward equality between whites and nonwhites. Soc Forces. 1970;49(1):108-17. https://doi.org/10.1093/sf/49.1.108

21. Jacobs B, Bigdeli M, Annear PL, Van Damme W. Addressing access barriers to health services: an analytical framework for selecting appropriate interventions in low-income Asian countries. Health Policy Plan. 2012 Jul;27(4):288-300. https://doi.org/10.1093/ heapol/czro38 PMID:21565939

22. Kang R, Columbo JA, Goodney PP. Assessing the appropriateness of carotid revascularization: in the eye of the beholder. JAMA Surg. 2017 Jun 1;152(6):573. https://doi.org/10.1001/jamasurg.2017.0090 PMID:28249068

23. Stone JS, Fukuoka H, Weinreb RN, Afshari NA. Relationship between race, insurance coverage, and visual acuity at the time of cataract surgery. Eye Contact Lens. 2018 Jan 15. https://doi.org/10.1097/ICL.0000000000000443 PMID:29369233 